Classification

Physics Abstracts

$68.55-73.40 \mathrm{~V}-61.16 \mathrm{D}$

\title{
Influence of substrate misorientation on the structural quality of lattice matched GaAs/ScYbAs/GaAs structures
}

\author{
Béatrice Guenais $\left({ }^{1}\right)$, Alain Poudoulec $\left({ }^{1}\right)$, André Guivarc' $h\left({ }^{1}\right)$, Yves Ballini $\left({ }^{1}\right)$, \\ Vincent Durel $\left({ }^{1}\right)$ and Cécile d'Anterroches $\left({ }^{2}\right)$
}

( $\left.{ }^{1}\right)$ Centre National d'Etudes des Télécommunications, Route de Trégastel, BP 40, 22301, Lannion, France

(2) Centre National d'Etudes des Télécommunications, Chemin du Vieux Chêne, BP 98, 38243 Meylan, France

(Received March 17, 1992; accepted May 22, 1992)

\begin{abstract}
Résumé. - Nous avons réalisé la croissance de 2 hétérostructures GaAs $(200 \mathrm{~nm}) / \mathrm{Sc}_{0,2} \mathrm{Yb}_{0,8} \mathrm{As}$ $(2 \mathrm{~nm}) / \mathrm{GaAs}$ par épitaxie par jets moléculaires; la première sur une surface nominale (001), et la seconde sur une surface vicinale $\left((001), 4^{\circ}\right.$ vers $(111)_{\mathrm{Ga}}$, charnière $\left.[-110]\right)$. Les structures ont été caractérisées par diffraction en réflexion d'électrons de haute énergie, rétrodiffusion d'ions et microscopie électronique en transmission. La couche de $\mathrm{Sc}_{0,2} \mathrm{Yb}_{0,8} \mathrm{As}$ est accordée à GaAs; sa croissance bidimensionnelle conduit à une très bonne qualité cristalline. Au contraire, le caractère tridimensionel de la réépitaxie de GaAs génère une grande densité de défauts plans. Pour les deux structures, nous avons comparé la nature des défauts, leur densité et leur répartition. Le choix d'une surface vicinale améliore la qualité de la réépitaxie de GaAs, et cette conclusion est discutée par rapport aux conditions de croissance particulières et à la morphologie des couches épitaxiées.
\end{abstract}

\begin{abstract}
Two GaAs $(200 \mathrm{~nm}) / \mathrm{Sc}_{0.2} \mathrm{Yb}_{0.8} \mathrm{As}(2 \mathrm{~nm}) / \mathrm{GaAs}$ heterostructures have been grown by molecular beam epitaxy; the first one onto a (001) nominal surface, and the second one onto a (001) vicinal surface $\left(4^{\circ}\right.$ off towards $(111)_{\mathrm{Ga}}$, tilt axis $\left.[-110]\right)$. The structures have been characterized by reflection high energy electron diffraction, Rutherford backscattering analysis and transmission electron microscopy. The $\mathrm{Sc}_{0.2} \mathrm{Yb}_{0.8}$ As layer is matched to GaAs and grows in a two-dimensional mode, leading to a high crystalline quality. But the GaAs overlayer contains a high density of planar defects, due to its three-dimensional growth. For the two structures, the nature of the faults, their density, and their distribution are compared. The quality of the GaAs overlayer is improved through growth on a vicinal surface. This conclusion is discussed with respect to the particular growth conditions and resulting morphology of the epilayers.
\end{abstract}

\section{Introduction}

Epitaxial III-V semiconductor / metal / III-V semiconductor heterostructures are potentially rich of applications in the field of electronic and optoelectronic devices. But the choice of a metallic 
material and the growth of such structures are rather challenging because of the difference in crystalline structure, polarity, bonding, chemistry, and possibly lattice mismatch between the metal and the semiconductor [1].

Indeed the combination of such different materials results in the formation of defects such as antiphase boundaries, dislocations, planar defects... Two classes of metallic materials have been studied: transition metal gallides and aluminides, with the $\mathrm{CsCl}$ structure such as $\mathrm{NiGa}$ [2-4] and $\mathrm{NiAl}$ [5], and the rare-earth monopnictides with the $\mathrm{NaCl}$ structure (RE-V) such as ErAs [6,7]. Contrary to the first class of metals, the lattice matching can be achieved by forming ternary RE$\mathrm{V}$ alloys for instance, $\mathrm{ErP}_{0.6} \mathrm{As}_{0.4} / \mathrm{GaAs}$ [8-12], $\mathrm{Sc}_{0.3} \mathrm{Er}_{0.7} \mathrm{As} / \mathrm{GaAs}$ [13], $\mathrm{Sc}_{0.2} \mathrm{Yb}_{0.8} \mathrm{As} / \mathrm{GaAs}$ [14] heterostructures.

In spite of this appreciable advantage, the quality of the structures have to be improved: efforts must focus particularly onto the GaAs overlayer, because its islands type growth $[11,15,16]$ on the metallic epilayer can give rise to the nucleation of defects. From this standpoint, the growth of the GaAs overlayer can be compared to the growth of GaAs onto a Si substrate.

In this paper, we study the effect of the GaAs substrate orientation - (001) or (001) $4^{\circ}$ off towards the $(111)_{\mathrm{Ga}}$ plane - on the quality of two $\mathrm{GaAs}(200 \mathrm{~nm}) / \mathrm{Sc}_{0.2} \mathrm{Yb}_{0.8} \mathrm{As}(2 \mathrm{~nm}) / \mathrm{GaAs}$ structures, where the $\mathrm{Sc}_{0.2} \mathrm{Yb}_{0.8} \mathrm{As}$ is lattice matched to GaAs [14]. The corresponding samples were characterized in situ by RHEED (reflection high energy electron diffraction), and ex-situ by Rutherford backscattering (RBS) and transmission electron microscopy (TEM), in order to appreciate their structural quality. This estimation is based on the determination of the nature of the defects, their density and their distribution. The origin of the defects with respect to the growth mode and the influence of the substrate misorientation are discussed.

\section{Experimental}

The two samples were grown in a Riber 2300 molecular beam epitaxy (MBE) chamber equipped with a rotating holder; the scandium was evaporated from a high temperature effusion cell (EPI).

Sample A was grown on a nominal (001) substrate. The surface is considered to be nominal because the misorientation is insignificant as measured by $\mathrm{X}$ ray-diffraction: the tilt angle is $0.4^{\circ}$ with a tilt axis close to [100]. Sample $B$ was grown on a misoriented substrate: the tilt angle is $\varepsilon=$ $3.8^{\circ}$ and the tilt axis $[-110]$.

First a $500 \mathrm{~nm} \mathrm{n}-\mathrm{GaAs}$ buffer layer was grown at $600^{\circ} \mathrm{C}$, then the substrate holder was cooled down to $430^{\circ} \mathrm{C}$ in an $\mathrm{As}_{4}$ flux, and the growth of a 7 monolayers thick $(2 \mathrm{~nm}) \mathrm{Sc}_{0.2} \mathrm{Yb}_{0.8} \mathrm{As}$ film was carried out at a deposition rate of $0.02 \mathrm{~nm} \mathrm{~s}^{-1}$. Last, a $200 \mathrm{~nm}$ thick GaAs overlayer was grown at $550^{\circ} \mathrm{C}$, at a $0.5 \mu \mathrm{m} \mathrm{h}^{-1}$ growth rate.

TEM observations were performed on cross-sections at $120 \mathrm{kV}$ for conventional TEM (Jeol $1200 \mathrm{EX}$ ) and $400 \mathrm{kV}$ for high resolution TEM (HRTEM) (Jeol $4000 \mathrm{EX}$ ); in addition, planview observations were performed at $120 \mathrm{kV}$. Cross-sections were prepared using ion thinning and plan-views using chemical thinning from the backside. The cross-sections are observed along the $[1-10]$ axis (which is the tilt axis for sample $B$ ). Our orientation rule consists in the [-110] axis pointing towards the observer. Figure 1 displays the orientation of the samples as a stereographic projection. In the text, the "upward" and "downward" directions will refer to the vicinal surface considered as a staircase.

\section{RBS results.}

The effect of the substrate misorientation is pointed out by comparing the $<001>$ aligned RBS spectra of the two samples. Figure 2 shows that a higher structural quality is obtained through the 


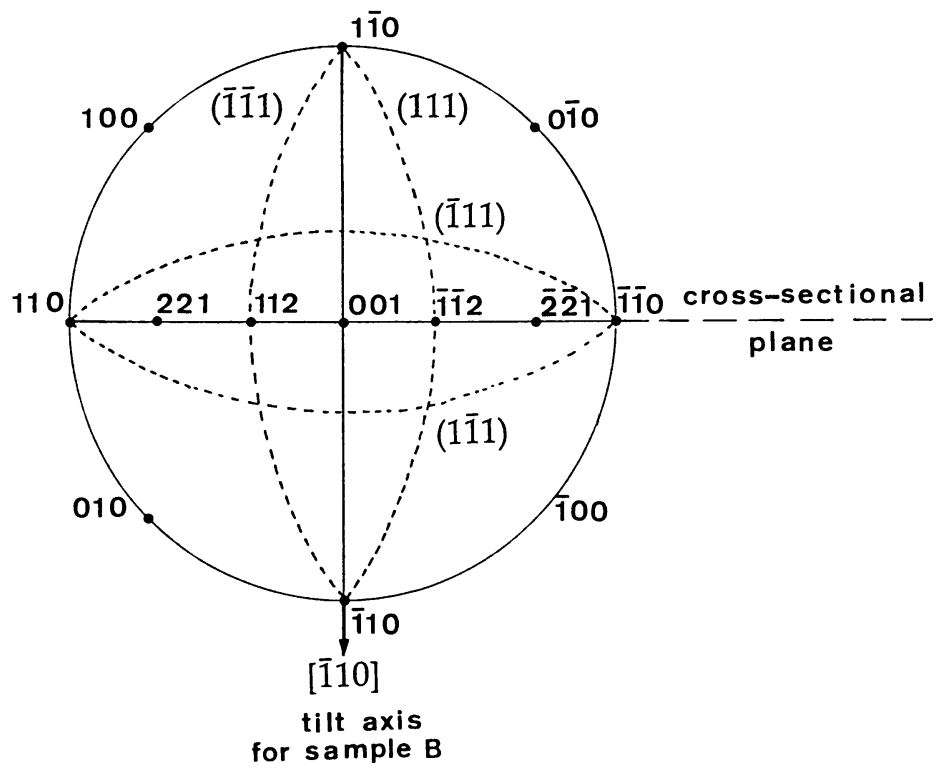

Fig. 1. - Stereographic projection showing the orientation of the samples.

use of a vicinal surface: at the overlayer surface (arrow S), there is a decrease of the $X_{\min }$ from $10 \%$ for sample A to $5 \%$ for sample B, and at the interface (arrow I, just below the metallic layer) from $20 \%$ to $8 \%$. The $X_{\min }$ is calculated by taking the ratio of the integrated yields in the aligned and random spectra. In order to assess the nature of the defects in the GaAs overlayer, and to explain the influence of the misorientation on the quality of the structure, an extensive TEM study was carried out.

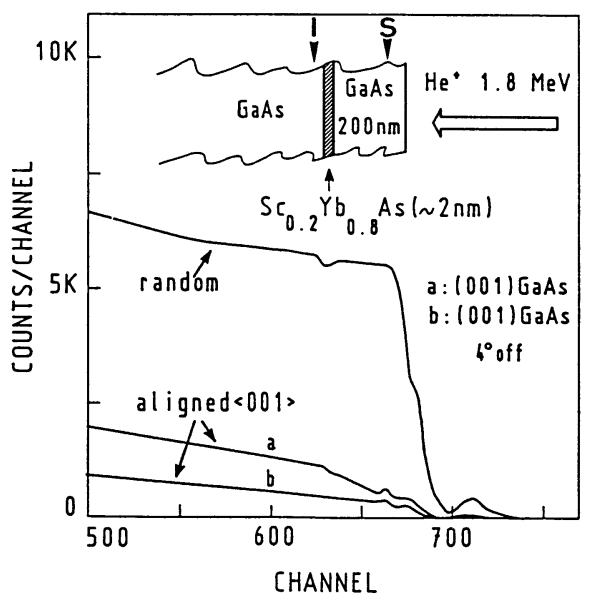

Fig. 2. - RBS / channelling spectra (1.8 $\left.\mathrm{MeV}, \mathrm{He}^{+}\right)$from samples $\mathrm{A}(\mathrm{a})$ and sample $\mathrm{B}(\mathrm{b})$. The two random spectra are quite similar. 


\section{TEM results.}

4.1 CROSS-SECTIONAL OBSERVATIONS ALONG [1-10]. - Note that this cross-section is cut perpendicular to the tilt axis for sample $B$.

Figure 3a shows a bright field image of sample A (slightly tilted from [-110] to get the 002 reflection excited). The $\mathrm{Sc}_{0.2} \mathrm{Yb}_{0.8} \mathrm{As}$ layer appears as a thin dark layer buried in GaAs. The TEM micrograph reveals a high density of defects in the GaAs overlayer: the dominant defects are planar defects, mainly microtwins ( 2 to $20 \mathrm{~nm}$ thick) and a few stacking faults, but the density of threading dislocations is very low. As the sample is viewed along the [1-10] axis, twins parallel to the (111) and (-1-11) planes can be imagined. Most of the defects propagate from the buried metallic layer all the way to the surface, but some of them mutually annihilate by intersection. Two sets of extra spots (arrow) associated with the microtwins are visible along the two $<111>$ directions on the diffraction pattern. As a result of a shape effect of the twin lamellae, the extra spots appear rather as streaks elongated in the $<111>$ directions.

Sample B (Fig. 3b) contrasts with sample A in the distribution of planar defects: the defects are confined in one of the two $\{111\}$ planes, leading to a reduction in the defect density. Clearly the better $X_{\min }$ value noted on the RBS spectra for the GaAs overlayer surface is related to this effect. Following the orientation rule, the plane containing the higher defect density is $(-1-11)$; the angle between this plane and the metallic layer surface is measured as $\approx 50^{\circ}\left(\approx 54^{\circ} 44^{\prime}-\varepsilon\right)$, so the dominating twin variant is the plane making the smaller angle with the metallic interface. The asymetry between the two $\{111\}$ planes is confirmed by the diffraction pattern, where only one set of extra spots appears.

In the two cases, the surface of the GaAs overlayer shows some roughness, more salient for sample A: although the ripple amplitude is about $30 \mathrm{~nm}$ for the two samples, the period is about $250 \mathrm{~nm}$ for A and $500 \mathrm{~nm}$ for B. No structural defects are visible in the metallic layer, which is lattice matched to GaAs; this is consistent with the very low value of the $X_{\min }(\approx 1.4 \%)$ we recently observed on $50 \mathrm{~nm}$ to $2 \mu \mathrm{m}$ thick $\mathrm{Sc}_{0.2} \mathrm{Yb}_{0.8}$ As films.

The first conclusion of these observations is that the density of planar defects is reduced through growth on a vicinal surface by suppression of the defects in one $\{111\}$ plane, and that there is a relation between the sense of the substrate tilt and the dominating twin variant.

4.2 LATTICE IMAGING ALONG [1-10]. - HRTEM was used to appreciate the interfacial quality of the structure, the crystalline quality of the metallic layer, and to study the nucleation of planar defects at the top metallic interface.

Sample A was studied at $120 \mathrm{kV}$ (not shown) and sample B at $400 \mathrm{kV}$, which offers a much better resolution and a higher transparency of the metallic layer to electrons.

Figure 4 is a HRTEM view showing the interfacial quality in sample B: the interfaces are abrupt at the atomic scale, and the monolayer steps (vicinal surface) at the bottom interface of the metallic layer are perfectly embedded in the structure (arrows). The only defects in the $\mathrm{Sc}_{0.2} \mathrm{Yb}_{0.8} \mathrm{As}$ layer were found to be pinholes (1 to $10 \mathrm{~nm}$ ) separating heavily facetted islands $(1.5 \mathrm{~nm}$ to $30 \mathrm{~nm}$ long). Figure 5 is a typical HRTEM view showing particularly small $\mathrm{Sc}_{0.2} \mathrm{Yb}_{0.8}$ As islands enclosed in GaAs. Islands are generally bounded by 2 (001) facets parallel to the interface, and by $4\{111\}$ facets inclined to the interface.

It is worth noticing that, in spite of the $4^{\circ}$ tilt angle, the bottom interface of the metallic layer is rather flat ((001) surface) often along more than $10 \mathrm{~nm}$, whereas the theoretical step spacing is 4.3 $\mathrm{nm}$. On the contrary, in the pinholes, the surface slope can reach $10^{\circ}$ (step spacing $1.6 \mathrm{~nm}$ ). We know that a regular step spacing does not generally occurs on a GaAs vicinal surface [17]. It seems that pinholes form where the steps on the GaAs surface become closer, whereas the metallic layer 

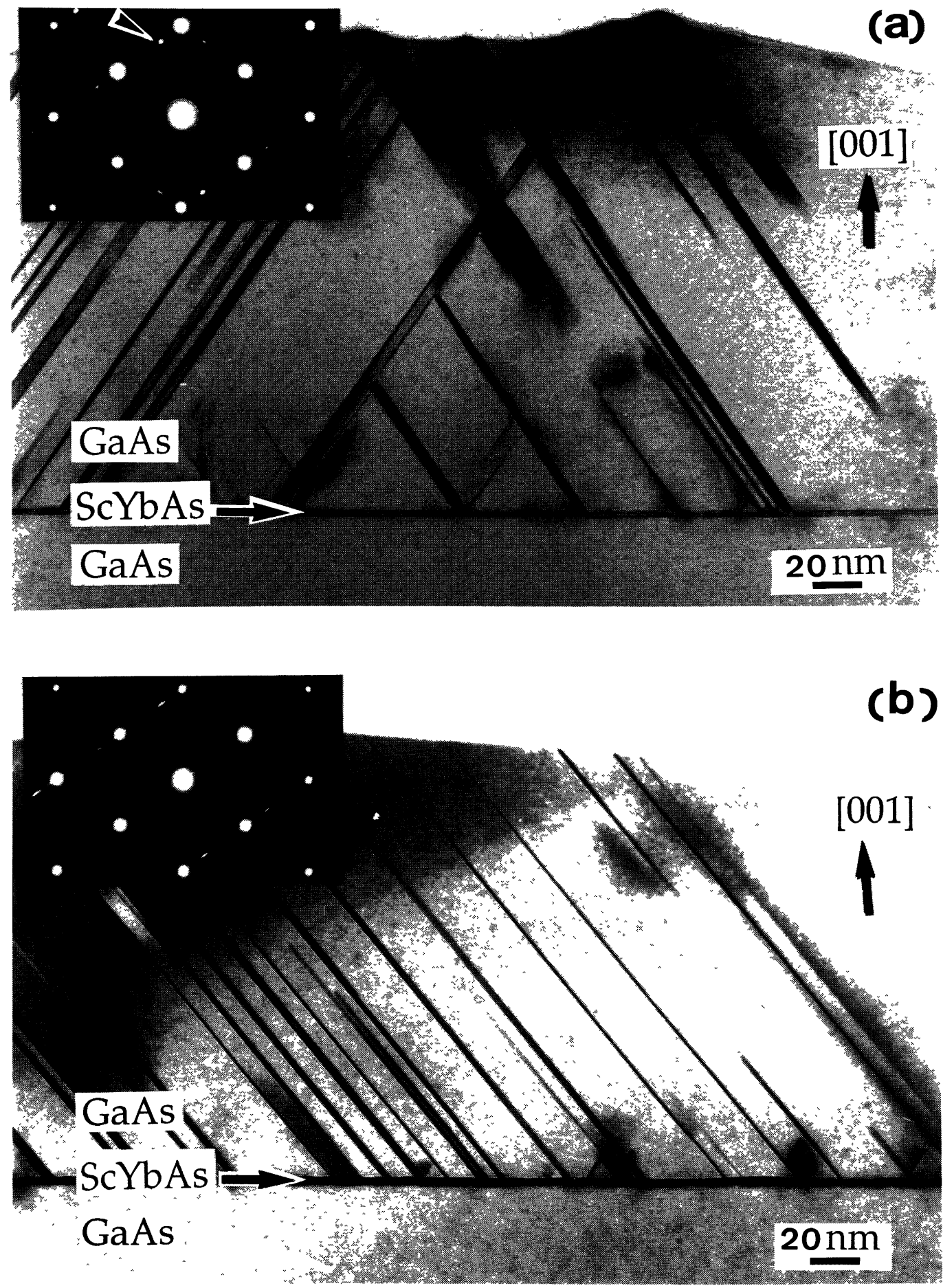

Fig. 3. - Cross-sectional bright field image of the whole structure, for sample A (a) and for sample B (b), showing the planar defects in the GaAs overlayer. $[-110]$ cross sectional micrograph. 


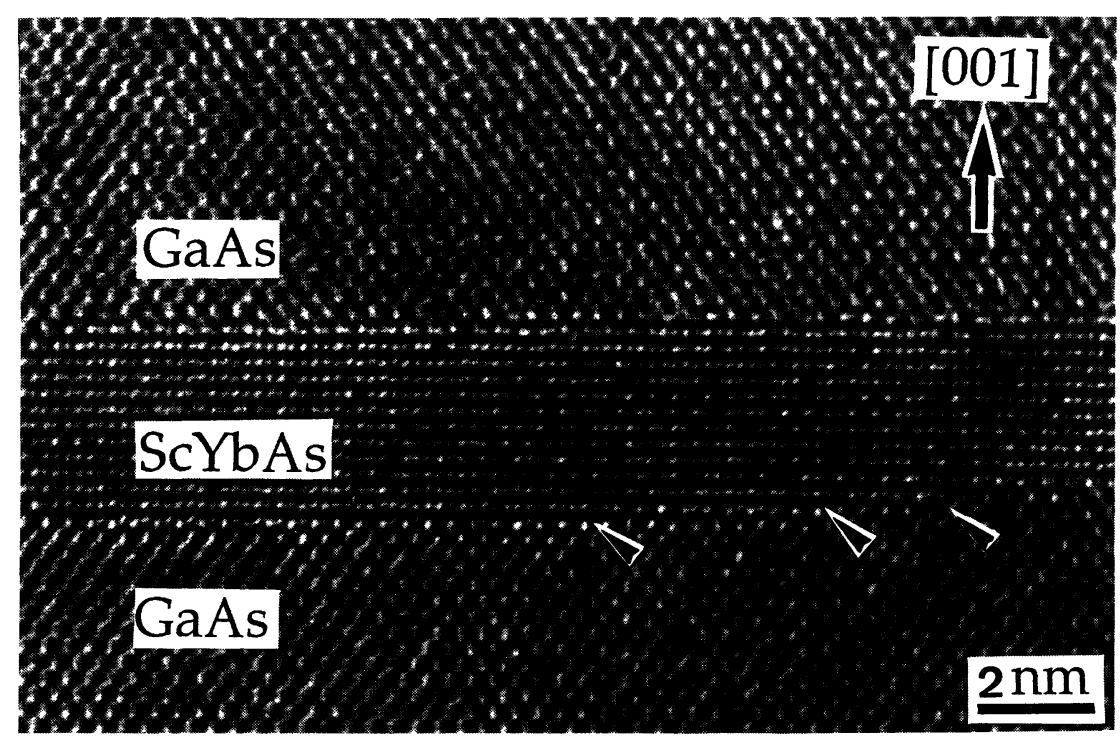

Fig. 4. - HRTEM (400 kV) image of the metallic epilayer for sample B. [-110] cross-sectional micrograph.

lies on flat terraces, so that there is a shift of 1 up to $7 \mathrm{GaAs}$ monolayers between two following islands.

Concerning the interfacial quality in sample $A$, the bottom interface of the metallic layer is abrupt at the atomic scale, with from place to place monolayer steps. The only defects are pinholes (about $5 \mathrm{~nm}$ in diameter), so that the metallic layer appears on the HRTEM very thin cross-section as composed of disjoined islands about $13 \mathrm{~nm}$ long.

The metallic layer, in both cases (A and B), was found to contain pinholes; the question arises whether pinholes are formed during the metallic layer growth (at $430^{\circ} \mathrm{C}$ ), or when the temperature is raised up to $550^{\circ} \mathrm{C}$ under $\mathrm{As}_{4}$ for the $\mathrm{GaAs}$ overlayer growth. In fact, the occurence of RHEED oscillations during the metallic layer growth for sample A proves a 2-dimensional growth (and allows an accurate determination of the metallic layer thickness), and the evolution from a streaky pattern to a slightly spotty one when the temperature is raised up to $550^{\circ} \mathrm{C}$ just before the overlayer growth suggests that pinholes are formed during this annealing.

The mean thickness, as observed by HRTEM is 8 monolayers for sample A $(2.3 \mathrm{~nm})$ and 11 monolayers $(3.1 \mathrm{~nm})$ for sample $B$, although the number of deposited layers is equal to 7 monolayers in the two cases; that suggests that pinholes cover about $12 \%$ of the surface for sample $A$ and $35 \%$ of the surface for sample B. The difference between the two samples can be attributed either to a slight temperature difference during the GaAs overgrowth (temperature measured with a precision of $20^{\circ} \mathrm{C}$ ) or to a particular morphology of the vicinal surface.

Concerning the $\mathrm{GaAs}$ overlayer, figure 5 shows a perfect alignment of GaAs crystal planes with those of the underlaying substrate. The defects are mainly microtwins, 2 to $3 \mathrm{~nm}$ thick (6 to $9\{111\}$ planes). We have studied about ten examples of defects, in very thin areas of sample $\mathrm{B}$, where islands and pinholes are well resolved. The defects are always located in the border of pinholes, whereas the quality is perfect in the pinholes (homoepitaxy). The dominating variant is confirmed to lean upwards the staircase (twin plane $(-1-11)$ ).

The top surface of the metallic layer is comparable whatever the sample: nominal or vicinal. 


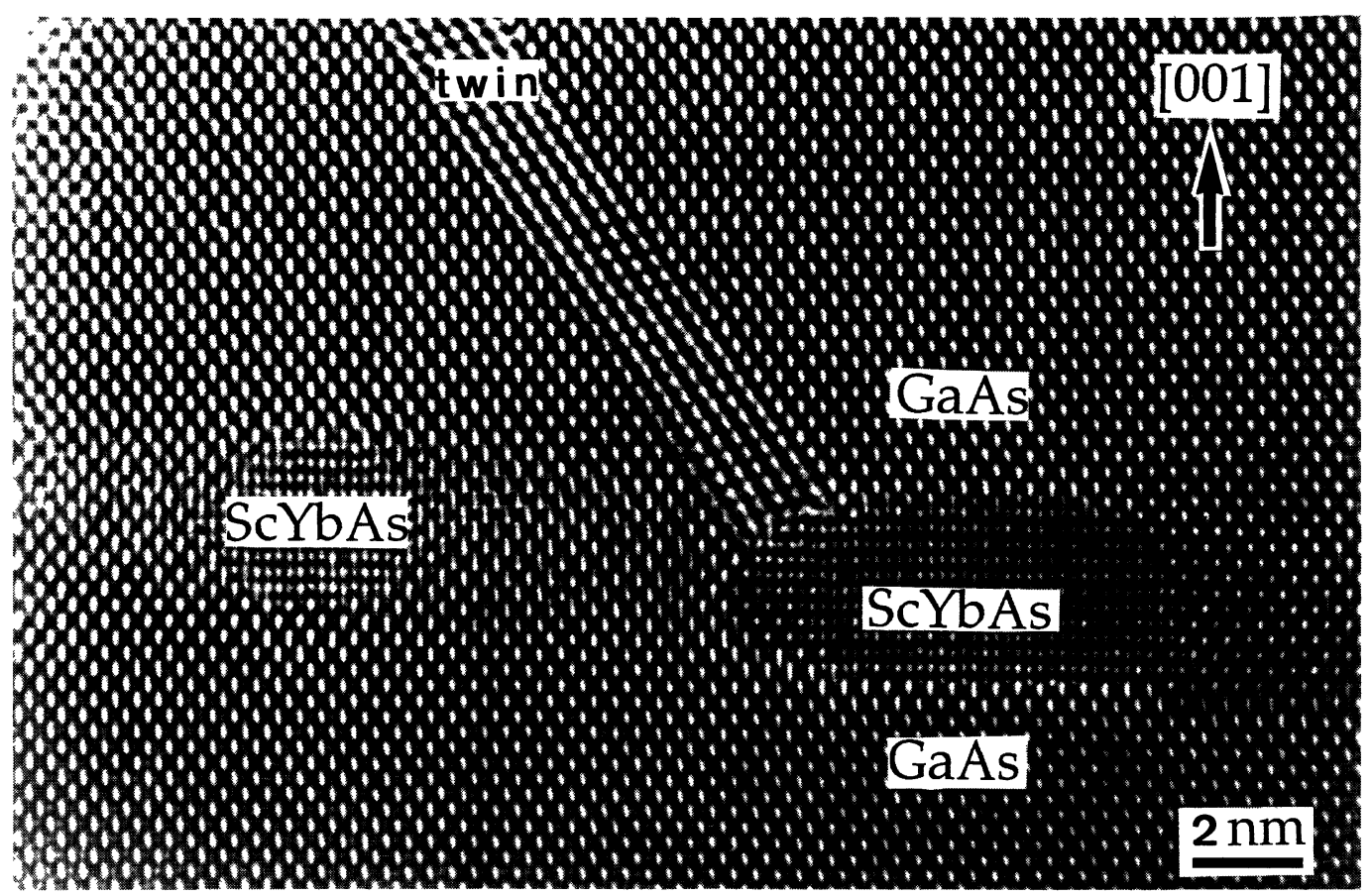

Fig. 5. - HRTEM $(400 \mathrm{kV})$ image of a thin area (sample B) where the $\mathrm{Sc}_{0.2} \mathrm{Yb}_{0.8} \mathrm{As}$ layer appears as disjoined islands.

The top interface is generally rather flat, with from place to place, bunching of steps occuring in the upward or downward direction; it is worth noting that twins are most frequently associated with those clusters.

4.3 Plan-VIEW OBSERVATIONS. - Cross-sections give a limited view of the sample so, in order to get an idea of the total density of planar defects in the overlayer, plan-views are necessary. Several authors report that growth of GaAs on tilted Si substrates lead to an anisotropy in the density of planar defects in two perpendicular TEM $<110>$ cross-sections $[18,19,20]$. So we got weak beam images of the GaAs overlayer for both samples using two perpendicular diffraction vectors [220] and [2-20]. The results for sample B are consistent with those results: a higher density of defects is noted in the two $\{111\}$ planes containing the $[-110]$ tilt axis. But the observation of sample A leads to unexpected results: indeed the same anisotropy is noted; the density is much higher in two out of the four $\{111\}$ planes. Figure $6 \mathrm{a}$ is a [220] weak beam where stacking faults and twins are marked by sets of parallel fringes; because of the high density of defects, many of them overlap. Figure $6 \mathrm{~b}$ is the [2-20] weak beam: the surface covered by fringes is much lower than in figure 6a; partial dislocations bounding the defects are distinct.

A high density of thin planar defects results in streaks at reciprocal points, normal to the habit plane of the defects [21,22].Tilting the sample away from [001] axis reveals indeed satellite spots in the $<110>$ directions. A dark field image using this satellite spots can be used to estimate the defect density in the different $\{111\}$ planes. Besides, microtwins result in extra spots which come out by properly tilting the sample first around [110] axis in the positive direction and then in the negative one, and second around [1-10] axis. A dark field image using one of these extra spots 

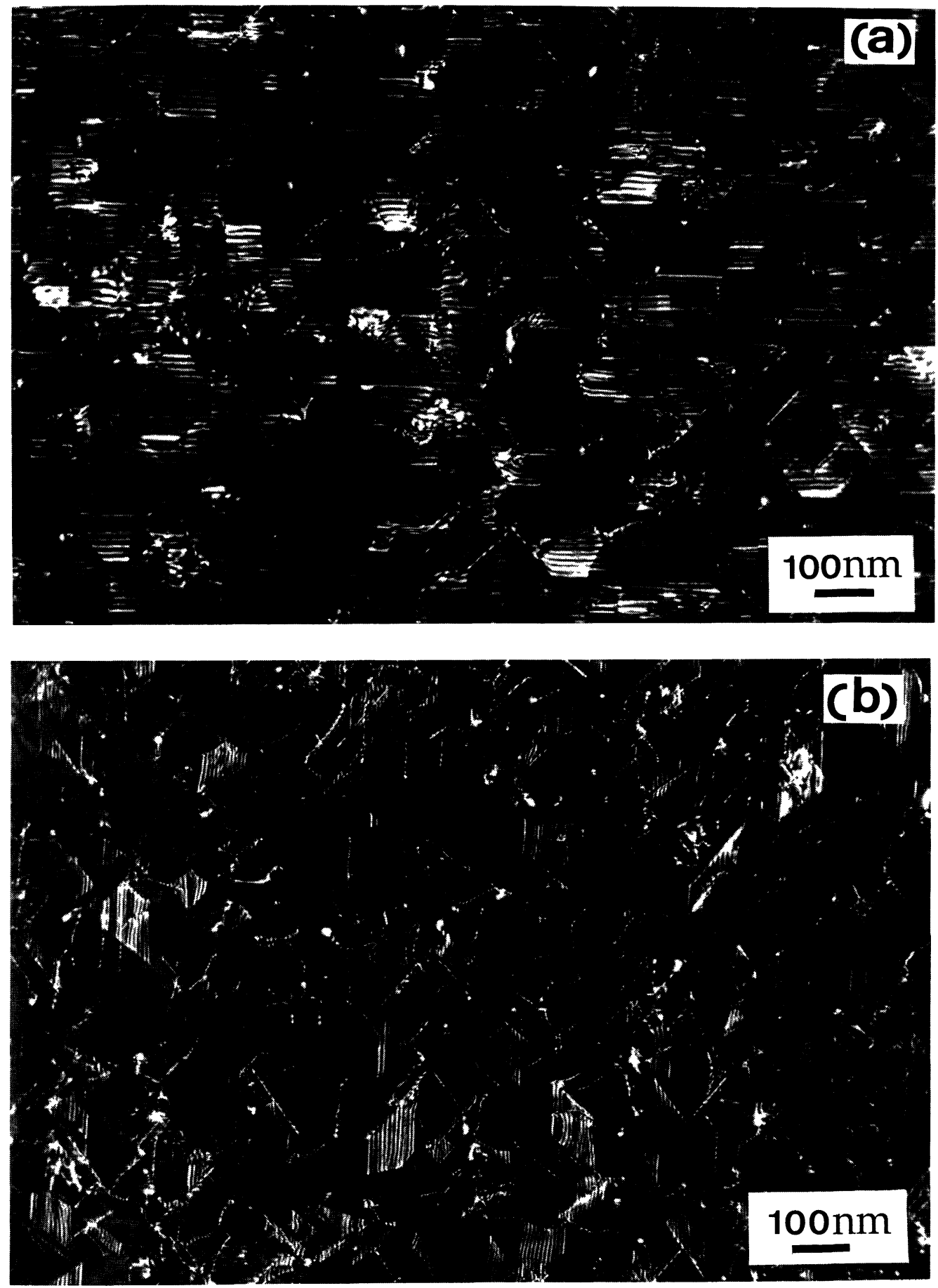

Fig. 6. - Weak-beam plan-view image for sample A: (a) defects in the (111) and (-1-11) plane; (b) defects in the $(-111)$ and $(1-11)$ planes. 


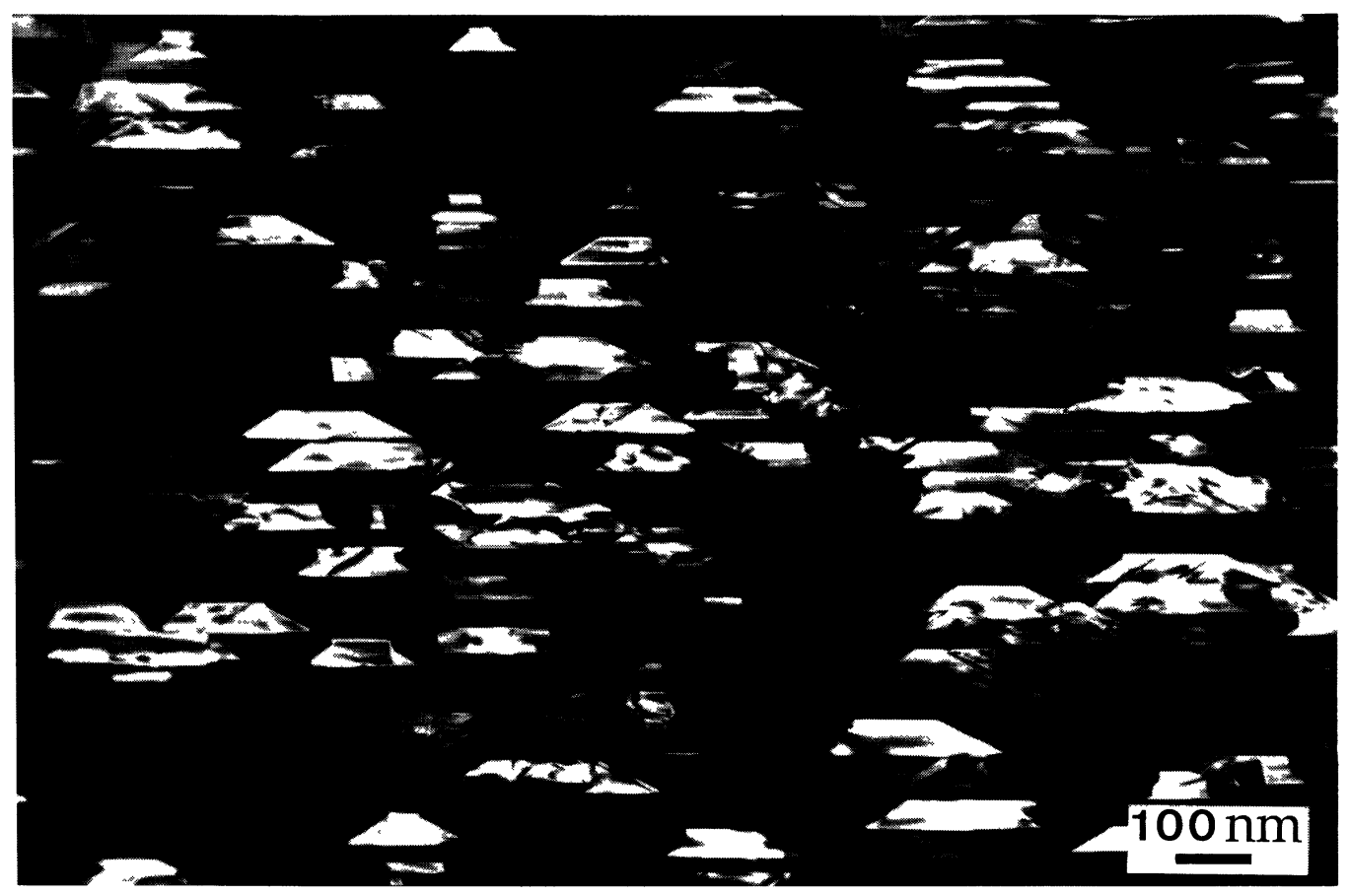

Fig. 7. - Dark field plan-view image using a twin variant reflection, for sample A: twins appear bright on the dark background.

yields one twin variant light on a dark background, as shown in figure 7, which is relative to sample A.

The defect density is a rough estimation because defects tend to overlap on the image. The plan-view observations confirm that a high majority of the faults are microtwins.

For sample $A$ the total density of faults in the GaAs overlayer is $\approx 1.3 \times 10^{10} \mathrm{~cm}^{-2}$, for a thickness of about $200 \mathrm{~nm}$. Their distribution is the following: $43 \%$ in (111) and in (-1-11) respectively, and $7 \%$ in $(1-11)$ and in $(-111)$ respectively. For sample $B$, the total density is $\approx 1 \times 10^{10} \mathrm{~cm}^{-2}$, distributed as follows: $85 \%$ in $(-1-11)$, and $5 \%$ in (111), in (1-11) and in $(-111)$ respectively. Note that the density of defects in (111) is divided by 10 for sample $B$ as compared to sample $A$; but the density in $(-1-11)$ is a little higher $\left(9 \times 10^{9} \mathrm{~cm}^{-2}\right.$ as compared to $6 \times 10^{9} \mathrm{~cm}^{-2}$ ).

Using a selective dark field, for example 002 which gives a high contrast between the $\mathrm{Sc}_{0.2} \mathrm{Yb}_{0.8}$ As layer and $\mathrm{GaAs}$, the metallic layer becomes visible through the GaAs overlayer (Fig. 8). Contrary to cross-section views where the metallic layer appears as disjoined islands, on the plan-views it appears as a continuous layer speckled with pinholes. The average surface covered by pinholes (which size is 5 to $25 \mathrm{~nm}$ ) is perfectly consistent with the previous estimation from cross-section observations for sample A and sample B.

\section{Discussion.}

5.1 ORIGIN OF PLANAR DEFECTS IN THE GaAs OVERLAYER. - The presence of planar defects in that matched structure confirms as a general rule that the lattice mismatch is not responsible 


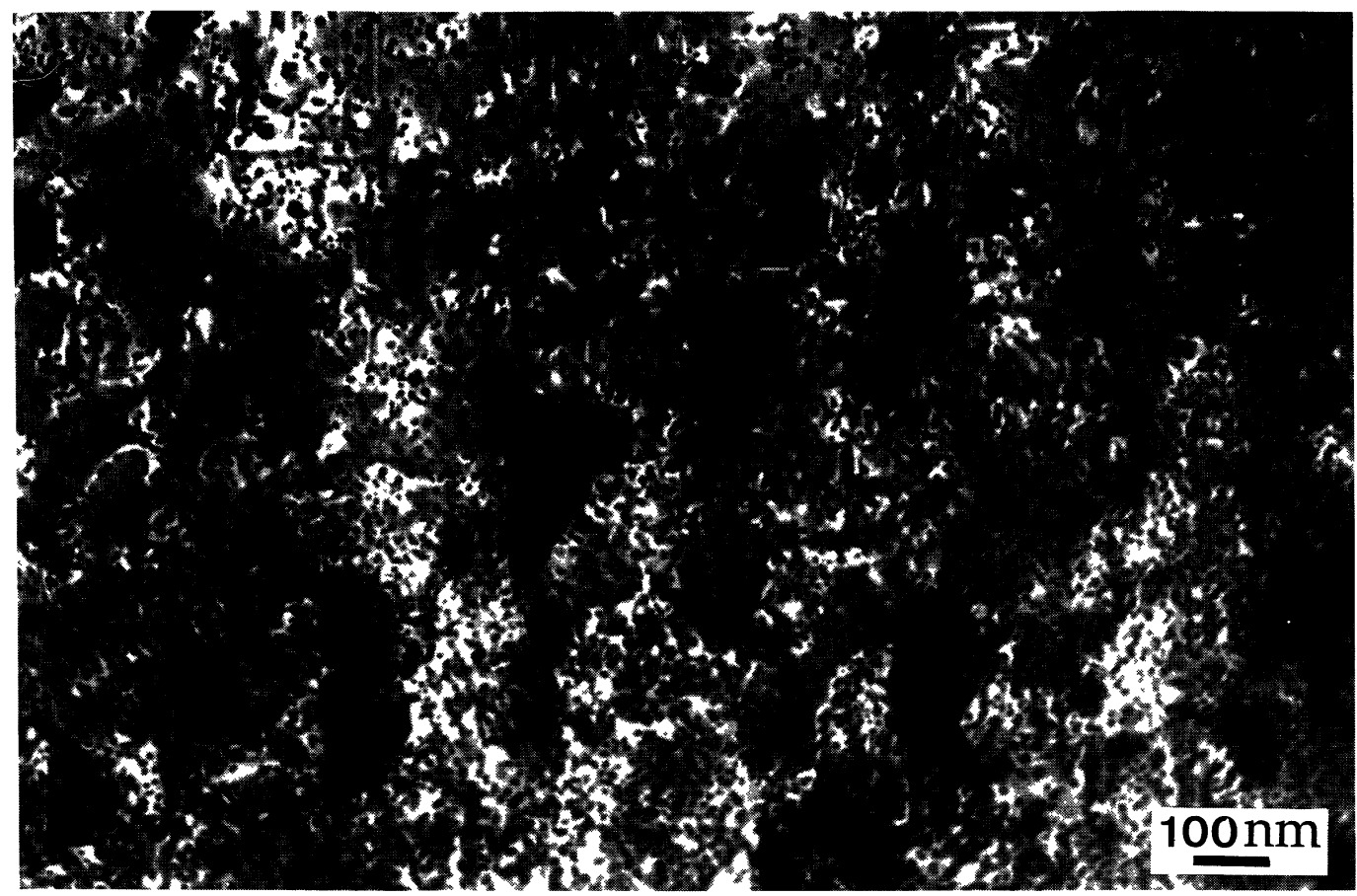

Fig. 8. - 002 dark field plan-view image for sample $A$; dark spots are pinholes in the $\mathrm{Sc}_{0.2} \mathrm{Yb}_{0.8} \mathrm{As}$ layer.

for the formation of twins and stacking faults, as was previously underlined for other systems [23]. It is generally admitted that there is a close relation between planar defects and a facetted 3-dimensional growth, as it is observed when growing an overlayer with a higher surface energy than the underlayer ( $\mathrm{GaAs} / \mathrm{Si}, \mathrm{GaAs} / \mathrm{metal})$; the initial nucleation of $\mathrm{GaAs}$ leads to nuclei facetted along low energy planes, i.e. $\{111\}$ planes [24].

The origin of defects in the "GaAs on $\mathrm{Sc}_{0.2} \mathrm{Yb}_{0.8} \mathrm{As}$ " structure will be discussed mainly from high resolution conclusions for sample $B$ :

Dominant defets are microtwins located in the vicinity of pinholes; they are associated with clusters of steps occuring upwards or downwards on the (001) $\mathrm{Sc}_{0.2} \mathrm{Yb}_{0.8}$ As surface. The metallic top surface does not reproduce at all the vicinal surface morphology of the GaAs substrate, so that in the case of sample $B$, the relation between the sense of the steps on the $\mathrm{Sc}_{0.2} \mathrm{Yb}_{0.8} \mathrm{As}$ surface and the dominating variant is not direct, as was suggested for GaAs/Si [25].

But the surface morphology of the sample just before the GaAs overlayer growth is not comparable to a (001) Si nominal or vicinal substrate: it must be pointed out that the surface is non planar and composed of 2 different materials, leading to a rather complex situation. Three types of surfaces are present:

$-\mathrm{a}(001) \mathrm{Sc}_{0.2} \mathrm{Yb}_{0.8} \mathrm{As}$ surface at the top of the metallic layer,

$-\{111\}$ facets of the $\mathrm{Sc}_{0.2} \mathrm{Yb}_{0.8}$ As layer,

-a (001) (sample A), or vicinal (sample B) GaAs surface in the pinholes.

So, the first point is that $\mathrm{Sc}_{0.2} \mathrm{Yb}_{0.8} \mathrm{As}\{111\}$ facets already exist on the surface when the $\mathrm{GaAs}$ overlayer growth begins.

Concerning the mechanism of formation of twins itself, 2 possibilities can be examined [23]:

a) stacking errors on $\mathrm{GaAs}\{111\}$ facets of 3 dimensional growing nuclei [26], 
b) a coalescence mechanism proposed by Matthews and Allison [27].

Considering these two mechanisms in the case of an epitaxy, leads to these remarks:

In the first case, the defects do not originate directly from the overlayer/substrate interface. In the second case, the coalescence of two GaAs $\{111\}$ facetted neighbouring islands of different size is considered: the smaller one is misoriented close to a twin relationship with the other; so we can infer that there will be a relation between the nucleation of these small misoriented nuclei and the local morphology of the substrate. When coalescence occurs, the small nucleus goes into a twin relationship with the first nucleus, atoms of the small one diffuse onto the $\{111\}$ facets of the larger one, leading to a twin lamella. Our observations suggest that the misoriented nuclei appear onto the metallic surface where a bunch of steps leads to a misorientation of about $30^{\circ}$ from (001), in one sense or the other.

As twins generally occur in the vicinity of pinholes, large GaAs islands are presumed to nucleate in the pinholes. Their morphology and their size is governed by several parameters which are the different growing rates normal to each facet and different growth modes : GaAs has a tendency to a 2-dimensional growth mode on (111) metallic surfaces of rare earth arsenides, whereas a tendency to a 3-dimensional growth is observed on (001) surfaces [11]. It is most likely that large GaAs islands develop $\{111\}$ facets which will move laterally and attach small islands nucleated on the (001) metallic surfaces.

\subsection{DISTRIBUTION OF PLANAR DEFECTS IN THE GaAs OVERLAYER.}

5.2.1 Sample A. - Such an anisotropy in the distribution of planar defects in the four twinning planes is surprising for sample A, which is grown on a nominal surface. Indeed, except for GaAs/ Si samples grown on vicinal surfaces, no such results concerning GaAs are reported. However a theoretical anisotropy in the shape of the nuclei resulting from the energy difference between $\mathrm{Ga}\{111\}$ facets((111) and $(-1-11))$ and As $\{111\}$ facets $((1-11)$ and $(-111))$ is supposed to lead to prism shaped nuclei [28], as was observed for GaP [23]. Taking into account the preceeding remarks concerning the nucleation of $\mathrm{GaAs}$ islands, and the different parameters having an influence on the size and the shape of the nuclei, we think that this anisotropy is related in our conditions to the particular aspect ratio of the GaAs islands.

It is worth noticing that, when comparing results from different authors, care must be taken to the growth parameters. The growth temperature, for example, was shown to have an influence on the GaAs island structure anisotropy [18].

5.2.2 Sample B. - In the case of sample B, the striking feature is the anisotropy in the density of planar defects (extending to the surface) in the two $\{111\}$ planes containing the $[-110]$ tilt axis $((111)$ and $(-1-11))$. The dominating twinning plane is the $(-1-11)$ i.e. the variant ,which leans toward the upper part of the staircase. Such an anisotropy was observed for $\mathrm{GaAs} / \mathrm{Si}$ on a vicinal surface $\left(4^{\circ}\right.$ off about $\langle 110>)$ [25]. However, the correlation between the dominating twin variant and the step orientation is exactly opposite; but we underlined just before that the $\mathrm{Si}$ vicinal surface was not comparable to the $\mathrm{Sc}_{0.2} \mathrm{Yb}_{0.8}$ As surface of sample $\mathrm{B}$.

The occurence of defects mainly on the (-1-11) plane is consistent with the stabilization of the corresponding facets of GaAs islands to the prejudice of (111) facets. From the outset, there is a strong asymmetry between (111) and (-1-11) facets of $\mathrm{Sc}_{0.2} \mathrm{Yb}_{0.8} \mathrm{As}$ islands: whereas the (111) facet will make an angle of $\left(35^{\circ} 16^{\circ}-\epsilon\right)$ with the normal of the sample, $(-1-11)$ will make an angle of $\left(35^{\circ} 16^{\prime}-\epsilon\right)$ resulting in an angle difference of $2 \epsilon$ and a growth rate difference normally to these facets (Fig. 9). 


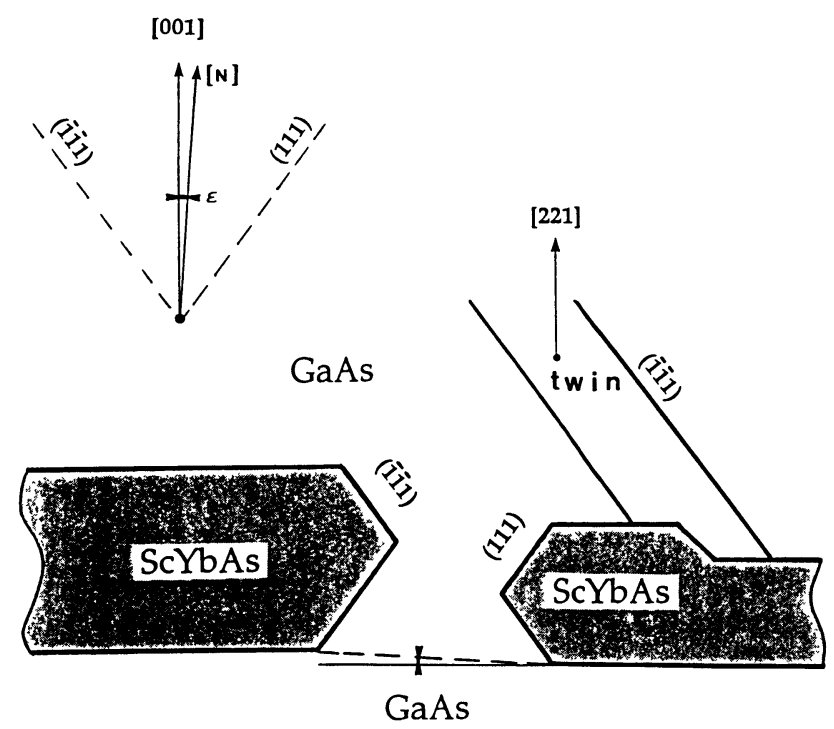

Fig. 9. - Schematic [-110] cross-sectional representation for sample B.

\section{Conclusions.}

6.1 CONCERNING THE METALLICLAYER GROWTH. - No defects are visible in the metallic layer, which is matched to GaAs. But we have brought out the crucial role of temperature in the morphology of thin (a few monolayers) metallic layer. A 2-dimensional growth is observed when the temperature is lower than a critical temperature of about $450^{\circ} \mathrm{C}$. But when the temperature is increased up to $550^{\circ} \mathrm{C}$ for the GaAs overlayer growth, pinholes appear in the $2 \mathrm{~nm}$ thick $\mathrm{Sc}_{0.2} \mathrm{Yb}_{0.8} \mathrm{As}$. The presence of these pinholes induces a seeded epitaxy of GaAs through the metallic layer, thus circumventing the problem of antiphase domains. The formation of pinholes in thin epilayers can be avoided by a proper choice of the temperature in each step of the growth.

6.2 CONCERNING THE OVERLAYER GROWTH, AND THE DEFECTS. - A high density $\left(10^{10} \mathrm{~cm}^{-2}\right)$ of planar defects lying in the $\{111\}$ planes and bounded by partial dislocations appear in the GaAs overlayer. Some anisotropy occurs in the distribution of defects either in the case of a nominal surface, or in the case of a vicinal surface. In the first case, defects lie preferably on two of the $4 \mathrm{GaAs}\{111\}$ planes i.e. (111) and (-1-11), whereas in the second case, the higher density of defects is in the $(-1-11)$ plane only.

Most of the defects are "coalescence microtwins", which nucleate where the $\mathrm{Sc}_{0.2} \mathrm{Yb}_{0.8} \mathrm{As}$ surface is particularly irregular (bunch of steps). These defects would de suppressed in the case of a more regular $\mathrm{Sc}_{0.2} \mathrm{Yb}_{0.8}$ As surface (nominal or vicinal).

However, persistent defects could be stacking faults or microtwins resulting accidentally from "stacking errors" as long as the GaAs nucleation will be 3-dimensional. Clearly a 2- dimensional growth mode would result in a reduction of the planar defect density. Optimized conditions of surface preparation, temperature and growth rate have to be found.

6.3 CONCERNING THE VICINAL SURFACE. - In the studied case, ( $200 \mathrm{~nm} \mathrm{GaAs})$, the use of a vicinal surface leads to a finite decrease in the defect density, because defects are suppressed in one 
of the four $\{111\}$ planes. This is all the more important because this plane is highly defective in the nominal sample. A different choice of the tilt parameters (tilt axis, tilt angle) could lead to a less significant decrease in the defect density. On the other hand, when defects lie in both (111) and (-1-11) planes, annihilation of defects by intersection at a short distance from the interface leads to a decrease in defect density with overlayer thickness. This possibility does not exist in the case of sample B. So the conclusions could depend on the thickness of GaAs. Moreover, our results suggest that conclusions will also depend on the morphology of the $\mathrm{Sc}_{0.2} \mathrm{Yb}_{0.8} \mathrm{As}$ layer (absence of pinholes) or the growth temperature conditions; a study of structures containing a much thicker $(40 \mathrm{~nm}) \mathrm{Sc}_{0.2} \mathrm{Yb}_{0.8} \mathrm{As}$ layer (abscence of pinholes) is now in progress, and first results show that the GaAs overlayer ( $200 \mathrm{~nm}$ thick) quality is also improved through the use of a vicinal surface, even if the growth mechanisms are quite different.

\section{Acknowledgements.}

The X-ray diffraction characterization by M. Baudet is greatfully appreciated. The authors also acknowledge P. Auvray and A. Regreny for discussions, G. Dupas and G. Ropars for help with sample fabrication.

\section{References}

[1] Sands T., Palmstrøm C.J., HaRbison J.P, Keramidas V.G., Tabatabaie N., Cheeks T.L., Ramesh R. and SILBERBERG Y., Mater. Sci. Rep. 5 (1990) 99.

[2] Guivarc'h A., Caulet J., Guenais B., Ballini Y., Guenais B., Poudoulec A. and Regreny A., J. Cryst. Growth 95 (1989) 127.

[3] Durel V., Guenais B., Ballini Y., Caulet J., Chomette A., Dupas G., Ropars G., Minier M., GUIVARC'H A. and REGRENY A., Inst. Conf. Ser. n 112 (1990) 129.

[4] Guenais B., Poudoulec A., DuRel V., Ballini Y. and GuivarC'H A., Inst. Phys. Conf. Ser. $\mathrm{n}^{\circ} 117$ (1990) 257.

[5] HaRbison J.P., Sands T., Tabatabaie N., Chan W.K., Florez L.T., Keramidas V.G., Appl Phys. Lett. 53 (1988) 1717.

[6 Palmstrøm C.J., Tabatataie N., Allen S.J., Appl. Phys. Lett. 53 (1988) 2608.

[7] RAlston J.D., ENNEN H., WenNekers P., Hiesinger P., HERRES N., SChNEIDER J., MÚller H.D., ROTHEMUND W., FUCHS F., SCHMÄLZIN J. and THONKE K., J. Electron. Mater. 19 (1990) 555.

[8] GuivarC'H A., CAULET J., LE CORRE A., Electron. Lett. 25 (1989) 1050.

[9] Le CORRe A., CAUlet J., GuivarC'H A., Appl Phys. Lett. 55 (1989) 2298.

[10] Caulet J., Le CORRE A., Guenais B., Ropars G., GuivarC'H A., J. Cryst. Growth 102 (1990) 309.

[11] Le CORRe A., Guenais B., GuIVARC'H A., LeCrosnier D., CAUleT J., MiniER M. and RoparS G., J. Cryst. Growth 105 (1990) 234.

[12] GuivarC'H A., Le CORRe A., CaUlet J., Guenais B., Minier M., Ropars G., BadOZ P.A. and DubOZ J.Y., Mat. Res. Soc. Symp. Proc. (1990) 160.

[13] Palmstrøm C.J., Mounier S., Finstad T.G. and Miceli P.F., Appl Phys. Lett. 56 (1990) 382.

[14] DuRel V., Caulet J., Ballini Y., Minier M., Guenais B., Dupas G. and GuivarC'H A., Proc. EuroMBE, Tampere (Finland) April 21-24 1991, Fp10.

[15] Zhu J.G., Palmstrøm C.J. and CARTer C.B., Mat. Res. Soc. Symp. Proc. 198 (1991) 177.

[16] Zhu J.G., CarTer C.B., Palmstrøm C.J., Mounier S., Appl. Phys. Lett. 56 (1990) 1323.

[17] Poudoulec A., Guenais B., d'ANTERroches C., Regreny A., J. Cryst. Growth 100 (1990) 529.

[18] Biegelsen D.K., Ponce F.A., Smith A.J., Tramontana J.C., J. Apply. Phys. 61 (1987) 1856.

[19] LEE J.W., TSAI H.L., J. Vac. Sci. Technol B5 (1987) 819.

[20] Vannuffel C., Beaucour J., ANDré J.P., Chevalier J.P., Inst. Phys. Conf. Ser. $\mathbf{n}^{\circ} 100$, section 3 (1989) 115. 
[21] GEVERS R., VAN LANDUYT J. and AMELinCKs S., Phys. Stat. Sol 18 (1966) 343.

[22] DE RidDER R., VAN LANDUYT J., GEVERS R., AMELINCKS S., Phys. Stat. Sol 30 (1968) 797.

[23] ERNST F., PIROUZ P., J. Mater. Res. 4 (1989) 834.

[24] ChoI D.K., TAKaI T., ERKoc S., Halicioglu T. and Tiller W.A., J. Cryst. Growth 85 (1987) 9.

[25] LaO P., TANg W.C., RaJKumar K.C., Guha S., MAdUKaR A., J. Appl Phys. 67 (1990) 6445.

[26] Hall M.J., ThOMPSON M.W., Brit. J. Appl Phys. 12 (1961) 495.

[27] MatTHEWS J.W., Allison D.L., Philos. Mag. 8 (1963) 1283.

[28] ChOI D.K., Koch S.M., TAKaI T., Halicioglu T. and TIlleR W.A., J. Vac. Sci. Technol B6 (1988) 1149. 